\title{
Genetics, diagnosis and management of colorectal cancer (Review)
}

\author{
MARINA DE ROSA ${ }^{1}$, UGO PACE$^{2}$, DANIELA REGA ${ }^{2}$, VALERIA COSTABILE ${ }^{1}$, \\ FRANCESCA DURATURO $^{1}$, PAOLA IZZO ${ }^{1,3}$ and PAOLO DELRIO ${ }^{2}$ \\ ${ }^{1}$ Department of Molecular Medicine and Medical Biotechnology, University of Naples 'Federico II', I-80131 Naples; \\ ${ }^{2}$ Colorectal Surgical Oncology-Abdominal Oncology Department, Istituto Nazionale per lo Studio \\ e la Cura dei Tumori, 'Fondazione Giovanni Pascale' IRCCS, I-80131 Naples; \\ ${ }^{3}$ CEINGE Biotecnologie Avanzate, I-80145 Naples, Italy
}

Received March 4, 2015; Accepted May 12, 2015

DOI: $10.3892 /$ or.2015.4108

\begin{abstract}
Colorectal cancer (CRC) is the third most common type of cancer worldwide and a leading cause of cancer death. Surgery represents the mainstay of treatment in early cases but often patients are primarily diagnosed in an advanced stage of disease and sometimes also distant metastases are present. Neoadjuvant therapy is therefore needed but drug resistance may influence response and concur to recurrent disease. At molecular level, it is a very heterogeneous group of diseases with about $30 \%$ of hereditary or familial cases. During colorectal adenocarcinomas development, epithelial cells from gastrointestinal trait acquire sequential genetic and epigenetic mutations in specific oncogenes and/or tumour suppressor genes, causing CRC onset, progression and metastasis. Molecular characterization of cancer associated mutations gives valuable information about disease prognosis and response to the therapy. Very early diagnosis and personalised
\end{abstract}

Correspondence to: Dr Marina De Rosa, Department of Molecular Medicine and Medical Biotechnology, University of Naples 'Federico II', via S. Pansini 5, I-80131 Naples, Italy

E-mail: marina.derosa@unina.it

Abbreviations: CRC, colorectal cancer; SNP, single-nucleotide polymorphism; CIN, chromosomal instability; MIN, microsatellite instability; EMT, epithelial-to-mesenchymal transition; CTC, computed tomography-colonography; CT, computed tomography; MRI, magnetic resonance imaging; CRM, circumferential resection margin; ERUS, endorectal ultrasound; CME, complete mesocolic excision; SEMS, selfexpandable metal stents; CLS, conventional laparoscopic surgery; SILS, single-incision laparoscopic surgery; crm: circumferential margin; TEM, transanal endoscopic microsurgery; TAMIS, transanal minimally invasive surgery; TME, total or partial mesorectal excision; CRT, chemoradiotherapy; RT, radiotherapy; pCR, pathological complete response rate; TNM, tumour, node and metastasis; NGS, nextgeneration sequencing

Key words: colorectal cancer, genetic heterogeneity, molecular signaling pathways, epithelial-to-mesenchymal transition, hereditary colorectal cancers, early diagnosis, personalised care, minimally invasive surgery, conventional laparoscopic surgery, robotic surgery care, as well as a better knowledge of molecular basis of its onset and progression, are therefore crucial to obtain a cure of CRC. In this review, we describe updated genetics, current diagnosis and management of CRC pointing out the extreme need for a multidisciplinary approach to achieve the best results in patient outcomes.

\section{Contents}

1. Molecular basis of CRC

2. Hereditary CRC and molecular diagnosis

3. CRC diagnosis

4. Management of colon cancer

5. Management of rectal cancer

6. Towards personalized care

7. Conclusion

\section{Molecular basis of CRC}

During colorectal adenocarcinoma development, epithelial cells from gastrointestinal trait acquire sequential genetic and epigenetic mutations in specific oncogenes and/or tumour suppressor genes, conferring them a selective advantage on proliferation and self-renewal $(1,2)$. So, normal epithelium becomes hyperproliferative mucosa and subsequently gives rise to a benign adenoma that evolves into carcinoma and metastasis in about 10 years (3).

Sporadic colorectal cancers (CRC), due to somatic mutations, account for about $70 \%$ of all CRCs. Familial CRC, a group of diseases in which patients do not present a Mendelian inheritance, but only a familial predisposition to develop cancer, are about 10-30\%, whereas hereditary diseases are about 5-7\% (4). Germline minor variant and/or single-nucleotide polymorphisms (SNPs) in oncogene or tumour suppressor genes are responsible for the familial types of the disease, while inactivating mutations in the same genes cause hereditary $\mathrm{CRC}(5,6)$. The main hereditary $\mathrm{CRC}$ syndromes are hereditary nonpolyposis colorectal cancer (HNPCC) and adenomatous polyposis syndrome (7).

Normal gastrointestinal epithelium is organized along a crypt-villus axis. A pool of colon stem and progenitor cells, the 
most undifferentiated cell types that are able of self-renewal and pluripotency, are located at the bottom of the crypt. These cells migrate along the crypt-villus axis, simultaneously differentiating in all epithelial colon lineages, such as Paneth, goblet, enterocytes and enteroendocrine cells. In about 14 days they arrive at the top of the villus and undergo programmed cell dead (apoptosis) $(8,9)$. This process is orchestrated from gradients of proteins, such as Wnt, BMP and TGF- $\beta$, together with extracellular matrix and stromal cells, that form the cell niche (10).

At the molecular level, CRCs are a very heterogeneous group of diseases. Loss of genomic integrity facilitates the accumulation of multiple mutations during the development of CRCs. Chromosomal instability (CIN), microsatellite instability (MIN), aberrant DNA methylation and DNA repair defects are all mechanisms involved in colorectal epithelial cell transformation and all play a significant role in CRCs (11-14).

Several altered molecular signaling pathways are involved in CRC onset, such as Wnt/APC/ $\beta$-catenin, phosphoinositide 3-kinase (PI3K)/AKT/glycogen synthase kinase-3 $\beta$ (GSK-3 $\beta$ ), transforming growth factor- $\beta$ (TGF)- $\beta /$ Smad, NF- $\mathrm{KB}$ or mismatch repair genes (MMR). These alterations confer individual susceptibility to cancer, and are responsible for responsiveness or resistance to antitumor agents $(15,16)$.

Wnt/ $\beta$-catenin pathway. It is the most frequently dysfunctional signaling in sporadic CRC. When Wnt ligand, a secreted glycoprotein, binds to its Frizzled (Fz) receptors, the multifunctional kinase GSK- $3 \beta$ is inactivated and $\beta$-catenin, that acts both as E-cadherin cell-cell adhesion protein and as a transcriptional activator, is stabilized, accumulated in the cytoplasm and finally translocated into the nucleus where it interacts with members of the lymphoid enhancer factor (LEF)/T-cell factor (TCF) and activates specific target genes. In the absence of Wnt-signal, casein kinase 1 (CK1) and the APC/Axin/GSK-3 $\beta$-complex, target $\beta$-catenin for ubiquitination and proteasomal degradation by its phosphorylation, so preventing its nuclear translocation $(17,19)$.

Wnt signaling contributes to tumour cell proliferation and inhibition of differentiation but it is also a critical mediator of endothelial function $(20,21)$. Norrin, a non-Wnt ligand, binds selectively to Fz receptor subtype-4 (Fz4) and induces canonical Wnt signaling in conjunction with cell surface co-receptor LRP5 $(9,10)$. Recently it has been demonstrate that Norrin is produced by human CRC, that it directly regulates endothelial cell proliferation and behavior, and that all of the critical components necessary to respond to Norrin signals are expressed by endothelial cells in the tumour microenvironment (22).

PI3K/AKT pathway. PI3K/AKT/PTEN pathway, often found dysfunctional in same sporadic and hereditary CRC, activates cell growth and inhibit apoptosis in response to several extracellular stimulations, such as growth factors, cytokines, hormones, heat and oxidative stress, hypoxia and hypoglycemia.

Binding of growth factor to its receptor induces self-phosphorylation and activation of receptor itself. Consequently,
$\mathrm{PI} 3 \mathrm{~K}$ is recruited at the plasma membrane level and so activated. Activated PI3K converts phosphatidylinositol (4,5)-bisphosphate (PIP2) into phosphatidylinositol $(3,4,5)$-trisphosphate (PIP3) and binding of PIP3 to AKT anchors it to the membrane allowing its phosphorylation and activation via phosphoinositide-dependent kinase-1 (PDK1) (23-25).

AKT acts in many cellular processes such as control of metabolism, translation, apoptosis and the cell cycle, by phosphorylating several target proteins, such as BAD (BCL-2 antagonist of cell death), caspase-9, mTOR (mammalian target of rapamycin), GSK3 and $\beta$-catenin (26-28). PTEN, a negative regulator of PI3K/AKT pathway, is a tumour suppressor gene, whose alterations are involved in several sporadic and hereditary CRC, that carries out its rule by dephosphorylating and downregulating PIP3 levels (29). Somatic mutations in this gene, such as small quantitative alterations of its expression, were found to be associated to different types of cancer (30). Furthermore, its germ-line mutations cause PTEN hamartoma tumors (PHTS) syndrome, a hereditary disorder predisposing patients to onset of multiple neoplasms (31-33). Recently it has been suggested that PTEN protein, as many others tumour suppressor genes, acts in a quantitative manner (34), and quantitative changes in its expression levels could have a role in phenotypic variability that PHTS patients have shown (35).

Ras/Raf pathway. Ras/Raf signaling determines mitogen-activated protein kinase (MAPK) activation, a group of serine/threonine kinase proteins that mediate signal transduction from plasma membrane to the nucleus, in response to several extracellular stimulations, such as growth and mitogenic factors $(36,37)$.

Ras genes $(\mathrm{H}, \mathrm{K}$ and $\mathrm{N})$ are localized on chromosome 12 and encode for small proteins with GTPase activity bound to the plasma membrane. Ras mutations usually activate Ras signaling by enhancing GTP levels and so mediating Raf proteins (A, B and C) phosphorylation and activation (38). Raf proteins, in turn, transduce signaling between MEK (1 and 2) and ERK (1 and 2) proteins, inducing transcription of genes involved in the cell cycle, and transcription regulation, such as Myc, cyclin-D/CDK $(39,40)$.

$N F-\kappa B$ pathway. NF- $\kappa B$ is a signaling pathway that takes part in cell proliferation and inflammation mechanisms. It consists of five subunits acting as transcription factors, RelA/p65, c-Rel, RelB, p50/NF- $\kappa \mathrm{B} 1$ and $\mathrm{p} 52 / \mathrm{NF}-\kappa \mathrm{B} 2$, that are able to dimerize and are sequestered in the cytoplasm by IкB proteins. The IKK complex, consisting of two catalytic (IKK $\alpha$ and IKK $\beta$ ) and one regulatory (IKK $\gamma$ ) subunits, represents the major regulator of this pathway. It acts by phosphorylating I $\mathrm{I} B$ proteins targeting them for proteasomal degradation. IкB degradation releases NF- $\mathrm{KB}$ proteins in the cytoplasm. Thus, they are free to translocate into the nucleus and activate transcription of specific genes $(41,42)$.

GSK-3 $\beta$ : a central regulator in cross-talk between the CRC pathways. All the molecular pathways cross-talk with each other and are regulated by one another. Interestingly, concerted regulation exists between NF- $\mathrm{KB}$, Wnt and other adhesion proteins such as E-cadherin. E-cadherin directly binds to $\beta$-catenin and NF- $\kappa \mathrm{B}$ sequestering them at the plasma membrane level and 
Table I. Genes involved in hereditary colorectal cancer syndrome.

\begin{tabular}{llc}
\hline Syndrome & \multicolumn{1}{c}{ Gene } & Hereditary \\
\hline $\begin{array}{l}\text { Hereditary non-polyposis } \\
\text { colorectal cancer (HNPCC) }\end{array}$ & $\begin{array}{l}\text { MLH1, MSH2, MSH6, MLH3, } \\
\text { MSH3 and PMS2 }\end{array}$ & Dominant \\
Turcot Syndrome (TS) & MMR or APC & Dominant or \\
& & Recessive \\
Familial Adenomatous Polyposis (FAP) & APC gene & Dominant \\
MUTYH-associated polyposis (MAP) & MUTYH & Recessive \\
Peutz-Jeghers syndrome (PJS) & STK11/LKB1 & Dominant \\
PTEN hamartoma tumors syndrome (PHTS) & PTEN & Dominant \\
Juvenile polyposis syndrome (JPS) & SMAD4-BMPR1A & Dominant \\
Polymerase Proofreading-Associated & POLD1-POLE & Dominant \\
Polyposis (PPAP) & & \\
\hline
\end{tabular}

subtracting them from the nucleus. When the transcription of WNT5A is activated by NF- $\mathrm{B}$, WNT5A binds its specific Wnt receptor inducing transcription of target genes such as Snail, CD44 and YAP1. Snail upregulation, in turn, represses E-cadherin expression releasing $\beta$-catenin and $\mathrm{NF}-\kappa \mathrm{B}$, available to translocate into the nucleus $(43,44)$.

GSK-3 $\beta$ is a protein that has a pivotal role in cross-talk between Wnt and NF- $\kappa \mathrm{B}(45)$. In colon and pancreatic cancer cells, GSK-3 $\beta$ positively regulates $N F-\kappa B$ activity and its activation confers a selective growth advantage to these cells, therefore acting as a tumour promoter (46). The molecular mechanisms underlying GSK-3 $\beta / N F-\kappa B$ interaction remain to be further investigated. More than 100 proteins, involved in a wide spectrum of cellular processes, are substrates of GSK-3 $\beta$, of which $\beta$-catenin and NF- $\kappa$ B inhibitor I $\kappa B$ are the most well known. Genes upregulated by $\beta$-catenin/TCF/LEF and/or NF- $\kappa \mathrm{B}$ include proto-oncogenes, such as c-Myc and cyclin-D1, and genes regulating cell invasion/migration, such as Snail, CD44 and MMP-7 (47).

Epithelial-to-mesenchymal transition (EMT): a common mechanism in molecular heterogeneity. Recently, it was suggested that EMT could be a common biological mechanism in cancers, representing a good target for therapeutic intervention. EMT consists in an essential phenotypic conversion of epithelial cells into cells with mesenchymal phenotype. It is a reversible process that often occurs during embryonic development and tissue remodeling and also plays a critical role in early event occurring in invasion and metastasis of many types of cancer, including CRC (48). EMT regulation is orchestrated by a group of transcription factors, including Snail, Slug, ZEB1 and Twist, but tumour microenvironment is also involved in this conversion through different signals, such as TGF- $\beta$, EGF, Wnt and Notch $(49,50)$.

During EMT, epithelial cells lose E-cadherin expression, that specifically guarantees the epithelial phenotype, destroy their intercellular adhesion, acquire mesenchymal characteristics and increase migratory and invasive properties (51). Furthermore, EMT program induces stem cell specific gene expression, thus promoting self-renewal capability $(52,53)$. Thus, understanding the specific molecular mechanisms sustaining EMT is of great relevance to block cancer progression.

TGF- $\beta$ pathway represents the main signaling that regulates EMT. Binding of TGF- $\beta$ to its receptor II (TGF- $\beta$-RII) promotes RI receptor recruitment on the complex at the membrane level. The activated complex induces Smad proteins phosphorylation, that, in turn, translocates into the nucleus, switching on transcription of specific genes, such as Snail, Slug, Twist and ZEB, all genes that are involved in EMT (54). We recently demonstrated that $\mathrm{LiCl}$, a GSK-3 $\beta$ inhibitor, induces mesenchymal-to-epithelial transition (MET) in vitro, suggesting that $\mathrm{LiCl}$ and GSK-3 $\beta$ could represent, respectively, interesting drug and target for CRC therapy (55).

\section{Hereditary CRC and molecular diagnosis}

Hereditary CRCs represent about 7-10\% of CRC and include HNPCC, adenomatous (FAP and MAP) and hamartomatous (PJS, JPS, PHTS) polyposis syndromes (56-58). The genes whose alteration are involved in their onset are now well known (Table I).

Differential diagnosis is essential for the management and cancer prevention of the affected individuals, because of each syndrome has its own distinctive organ-specific manifestation and each requires a different surveillance strategy.

Patients with germline causative CRC mutations have a high lifetime risk of gastrointestinal and extra-intestinal carcinoma and their first-degree relatives have a high risk of recurrence of the syndrome. Characterization of a causative mutation in leukocyte DNA is essential for the differential diagnosis among the various hereditary CRC syndromes, assessment of the risk of recurrence (autosomal dominant versus autosomal recessive inheritance), determination of familial cancer risks based on gene-specific cancer associations and predictive testing of asymptomatic at risk individuals.

The role of the molecular genetic findings in treatment decisions, on the other hand, is limited because identification of a germline mutation rarely allows any estimation of the likely course of the disease. According to the international literature 
data, we suggest that next-generation sequencing (NGS) is today the best and the most efficient technique for molecular diagnosis of hereditary colorectal polyposis syndrome, and hereditary/familial CRC. Moreover, even if no mutation is found, the patient with hereditary cancer syndromes still needs to be treated appropriately and clinical follow up should be initiated even before mutation testing is complete (59).

\section{CRC diagnosis}

CRC clinical manifestations. Clinical manifestations of CRC depend on the location of the lesion. Both right and left colon lesions occasionally cause hematochezia, but more often bleeding is occult, causing anemia and fatigue. Rectal lesions cause hematochezia, bleeding and tenesmus. Up to $30 \%$ of patients with colorectal carcinoma are primarily diagnosed in an acute stage with sub/obstructing symptoms $(60,61)$. In $20-25 \%$ of patients with colonic cancer and in $18 \%$ of patients with rectal cancer, metastases are present at the time of the first diagnosis $(62,63)$. Although liver represents the most common metastases localization in CRC patients, $2.1 \%$ of these patients show lung metastases (64), with frequency about three times higher for patients with rectal cancer than for patients with colon cancer.

Clinical diagnosis and staging. Appropriate diagnosis and staging are crucial to ensure a correct treatment strategy. In the last 10 years the mortality rate of CRC has decreased by more than $20 \%$ due to the rising developments in diagnostic techniques and optimization of surgical, adjuvant and also palliative therapies (62). A complete colonoscopy up to the cecum, coupled with biopsy for histopathological examination, is considered the gold standard to diagnose colorectal lesions, in view of its high diagnostic performance $(65,66)$. This procedure allows the tumour localization and possibly the endoscopic excision of polyps, so simultaneously representing a diagnostic and a therapeutic opportunity (67).

The best results are exhibited for lesions $>6 \mathrm{~mm}$, showing sensitivity and specificity of about 98 and 99\%, respectively (68). However, a substantial proportion of patients will have an incomplete colonoscopy due to poor bowel preparation, poor patient tolerance, obstruction or other technical difficulties. In these cases, additional computed tomography-colonography (CT or CTC) can contribute to the CRC diagnosis $(69,70)$, as a potential alternative to the endoscopy, especially in patients with stenotic tumour and/or when colonoscopy turn out to be incomplete or difficult. Furthermore, CT has been established as a highly sensitive and specific diagnostic modality for lesions $>10 \mathrm{~mm}$ (71).

Despite such promising data, CTC does not offer the opportunity of taking biopsies or immediate polypectomy and the patient needs to return for a colonoscopy, in case of detected lesions. Tumours with distal extension to $15 \mathrm{~cm}$ (as measured by colonoscopy) from the anal margin are classified as rectal, while more proximal tumours are classified as colonic. Rectal digital examination can identify cancers up to $8 \mathrm{~cm}$ above the dentate line. Imaging plays a crucial role in the diagnosis, staging assessment for specific (e.g., neoadjuvant) therapy and follow up of patients with colon and rectal cancer with the main function of defining the locoregional extent, identifying synchronous lesions and distant metastases.

CRCs are classified according to local invasion depth (T stage), lymph node involvement ( $\mathrm{N}$ stage) and presence of distant metastases (M stage) (72). These stages are combined into an overall stage definition, which provides the basis for therapeutic decisions. Specifically, classification according to tumour, node and metastases (TNM) and Union Internationale Contre le Cancer (UICC) stage offers valuable prognostic information and guides therapy decisions.

The most used imaging modalities for staging of CRC are chest/abdomen/pelvis CT $(63,73,74)$ and magnetic resonance imaging (MRI). CT has a sensitivity of $74-84 \%$ and a specificity of $95-96 \%$ in detection of CRC liver metastases $(64,74)$. MRI evaluates liver lesions $<1 \mathrm{~cm}$ in size with a sensitivity of $80-88 \%$ and a specificity of $93-97 \%$ (75). However, CT has shown to be poor in identifying nodal disease $(76,77)$. Its specificity for lymph node staging is $55 \%$, while the sensitivity is $76 \%$ (64). Nodal size is too unreliable as a predictor for malignancy and should not be used as an absolute tool to define whether lymph nodes are involved or not. In preoperative imaging of rectal cancer, MRI is recommend for local staging $(78,79)$ and whole body CT for detection of distant metastases (80-82).

MRI is able to accurately define the local extension of rectal tumour, the mesorectal fascia involvement, circumferential resection margin (CRM) (78) and the relationship of the tumour to the sphincter complex. It has a high accuracy in detecting extramural spread and in identifying tumours with good ( $<5 \mathrm{~mm}$ invasion) vs. poor ( $>5 \mathrm{~mm}$ invasion) prognostic features. Moreover, MRI represents the most accurate imaging tool for identifying nodal disease with a sensitivity of $85 \%$ and specificity of $97 \%$, not by a size criteria but better with a definition of border irregularity and heterogeneity. MRI therefore is essential to accurately stage patients with rectal cancer in order to select the indication to a preoperative treatment or defining the extent of radical surgery.

Endorectal ultrasound (ERUS) is another well established modality for the evaluation of the integrity of the rectal wall layers. With accuracies for $\mathrm{T}$ staging ranging between 69 and $97 \%$, endorectal ultrasonography is currently the most appropriate imaging modality for the assessment of T1 tumours. It may also detect regional adenopathy, with a lower accuracy to identify nodal involvement compared to both CT and MRI. As described by Swartling et al (83), the combination of MRI with ultrasound improves diagnostic accuracy.

\section{Management of colon cancer}

Primary colon cancers without systemic disease are treated mainly by surgery with complete mesocolic excision (CME) $(84,85)$ with arteries and veins ligated as close as possible to the main vascular trunk to have lower local recurrence rate and improved survival $(86,87)$. The concept of CME is similar to the total mesorectal excision (TME) for rectal cancer and allows an excellent oncological outcome with a 5-year cancer specific survival rate of $91.4 \%$ in stage II, and $70.2 \%$ in stage III CC (87). Colonic segmental resection 
is performed according to the site of the tumour; right hemicolectomy transverse colectomy, left hemicolectomy or total colectomy are the most common surgical procedures and it is always indicated in absence of metastases.

In the emergency setting, when presenting symptoms of obstruction, perforation and bleeding, segmental colectomy for resection of the tumour, with or without fecal diversion, is indicated. In elderly patients with acute malignant colonic obstruction in whom emergency surgery carries high risks of morbidity and mortality, in presence of unresectable metastatic lesions or as initially palliation of obstructing CRC, the use of self-expandable metal stents (SEMS) is gaining wide acceptance, also to allow a quick start of neoadjuvant chemotherapy or chemoradiation. The colonic stent insertion effectively decompresses the obstructed colon and surgery can be performed electively at a later stage avoiding a derivative ostomy, whenever possible (88-90).

Minimally invasive surgery is a safe and valid alternative to open surgery in the treatment of colon cancer with less postoperative pain, shorter duration of ileus and hospital stay. Also, randomized trials have demonstrated similar oncologic outcomes compared with open surgery. Conventional laparoscopic surgery (CLS) with CME, is today considered a safe technique and spread all over the world; single-incision laparoscopic surgery (SILS) appears to offer cosmetic advantages over CLS, with no compromise of surgical morbidity, oncological appropriateness or increased cost. Recent studies show that colorectal resections for cancer with SILS have short-term results comparable with CLS (91-95). Laparoscopic and robotic surgery for colon surgery have the same advantages in terms of faster recovery, but robotic-assisted colectomy significantly increases the costs of care without providing clear reductions in overall morbidity or length of stay, so a critical appraisal of the benefits offered in comparison with the resources consumed is undergoing $(96,97)$.

\section{Management of rectal cancer}

Rectal cancers can be divided into 4 groups: very early (some cT1), early (cT1-2, some cT3), intermediate (most cT3, some cT4) and locally advanced (some cT3, most cT4) but, for cancer staging we have to consider other important factors as distance from the anal verge, circumferential margin (crm) (98), nodal (cN)-stage, vascular and nerve invasion. Rectal cancer has a distal extension to $15 \mathrm{~cm}$ or less from the anal margin.

Treatment of very early rectal cancer. For the very early tumours (stage 1) and for the malignant polyps [Haggitt 1-3, T1 sm 1(-2?) N0], after adequate staging by ERUS, rectal MRI and CT scan, local excision could be considered, by means of traditional transanal procedure or by a video-assisted technique, both transanal endoscopic microsurgery (TEM) $(99,100)$ or transanal minimally invasive surgery (TAMIS) $(101,102)$.

Treatment of early rectal cancer. Surgery is the mainstay of treatment for early rectal tumours: TME is the appropriate procedure, both performed laparoscopically or open. Minimally invasive approach is slow to become diffusely utilized due to the long learning curve of laparoscopic surgery, when compared to open surgery it has shown better short-term clinical outcomes and some evidence of comparable oncologic results are now arising. Several trials have compared the different surgical techniques in terms of oncological radicality and survival outcome.

The CLASICC trial comparing laparoscopic to open surgery and including rectal resections, showed an increased positivity of the CRM in the laparoscopic group, but no significant differences in terms of survival rates after 6 years of follow-up when compared to open surgery $(103,104)$.

The COREAN trial (105) compared laparoscopy to open surgery after neoadjuvant chemoradiotherapy (CRT), showed no significant differences in terms of CRM positivity between 2 groups: $4.1 \%$ in the open group and $2.9 \%$ in the laparoscopic group.

The COLOR II study (106) showed a higher CRM positivity in the open surgery compared to laparoscopic group (22 vs. $9 \%, \mathrm{P}=0.014$ ), but no significant differences in terms of morbidity, mortality, and complication rates.

More studies are therefore needed to verify the superiority of one surgical technique over the others in terms primarily of oncological radicality and disease free survival.

Robotic surgery, finally, would seem to overcome the technical difficulties of laparoscopy, but there are still no reliable data demonstrating its superiority in terms of oncological results compared to open and laparoscopic surgery $(29,30,107,108)$

Robotic approach resulted in a lower percentage of conversion to open surgery $(109,110)$ and a superiority of robotic rectal resection in recovery of urinary voiding and sexual function (111-113). Data from two multicentric studies comparing robotic to laparoscopic TME (ROLARR and COLRAR) are ongoing and results are awaited to better define the role of robotic rectal surgery (114).

Treatment of intermediate and locally advanced rectal cancer. Neoadjuvant therapy in [(C)RT] allows radical surgery with TME also in locally advanced rectal cancer. This approach has led to a reduction of recurrence rates from $30-40 \%$ of a few decades ago down to 5-10\% or even lower figures. Adjuvant and neoadjuvant approach to locally advanced rectal cancer has been long debated: while a NIH Consensus Conference in the early 1990s stated that the most appropriate treatment was postoperative CRT $(115,116)$, in Europe numerous trials supported RT before surgery with moderately high and never lower than $30 \mathrm{~Gy}$ doses. This approach has also led to a decrease of the local recurrence rate (117).

Neoadjuvant chemoradiation became standard practice after the publication of the results of the German trial (118). The choice between standard long course chemoradiation and short course radiation is still related to the 'tradition' of the group.

Several studies were performed, many are still in progress and many of them showed that both options have to be considered valid $(118,119)$.

The Stockholm III trial $(120,121)$ regarding the fractionation of radiotherapy (RT) and timing of surgery for rectal cancer, has randomized patients to preoperative short-course RT with two different intervals to surgery: $5 \times 5 \mathrm{~Gy}$ and surgery within 1 week (group 1) or after 4-8 weeks (group 2) 
or long-course RT 25x2 Gy and surgery after 4-8 weeks (group 3). These two different preoperative RT regimens has shown that patients of group 1 were associated with more postoperative complications than the other and that the experimental schedule (group 2) was shown to be feasible and as safe as the established treatments. However, results about local recurrences, will be available later in 2015 .

Bujko et al (122) published long-term results of a randomized trial comparing preoperative short-course RT with preoperative conventionally fractionated chemoradiation for rectal cancer. Chemoradiation $(50.4 \mathrm{~Gy}$ in 28 fractions of $1.8 \mathrm{~Gy}$, bolus 5-fluorouracil and leucovorin) and surgery 4-6 weeks later did not increase survival, local control or late toxicity compared with short-course RT alone.

Ngan et al (123) published the results of a randomized trial comparing short RT and CRT long-course having as end point the local recurrence in $\mathrm{T} 3$ rectal cancer. Two different treatments were offered: in one, patients underwent pelvic RT 5x5 Gy in 1 week, early surgery and six courses of adjuvant chemotherapy; in the other, long course RT $50.4 \mathrm{~Gy}$, $1.8 \mathrm{~Gy} /$ fraction, in 5.5 weeks, with continuous infusional fluorouracil $225 \mathrm{mg} / \mathrm{m}^{2}$ per day, surgery in 4-6 weeks, and four courses of chemotherapy were given. The final results showed that there were not significant differences between the two schedules in terms of local recurrence, except that long $\mathrm{RT}$ was more effective in reducing local recurrence only for distal tumours.

Siegel et al (124) published a randomised study comparing short RT plus TME-surgery within 5 days in the first group and long RT with continuous infusion 5-fluorouracil plus TME-surgery 4-6 weeks later in the second group. After surgery all patients had adjuvant chemotherapy for 12 weeks. No difference was shown in terms of local recurrence rate between the two groups.

The choice of chemotherapy in neoadjuvant treatment in locally advanced rectal cancer. 5-fluorouracil (5-FU) in infusion is now the drug commonly used in neoadjuvant treatment. The oral capecitabine gives the same effects and is much easier to manage by both the oncologist and patient (125).

Combinations of 5-FU and other cytotoxic drugs such as oxaliplatin and irinotecan, and targeted drugs, have been extensively explored during the past decade. Multiple phase II studies in the so-called 'locally advanced rectal cancer' have claimed better results [more down-sizing, higher pathological complete rates (pCR)]. When cetuximab was added to CRT with capecitabine and neoadjuvant chemotherapy with capecitabine-oxaliplatin in a randomized phase II study, the primary endpoint, pCR rate, was not increased, but more radiological responses ( 89 vs. $72 \%, \mathrm{P}=0.002)$ and improved OS (96 vs. $81 \%$ at 3 years, $\mathrm{P}=0.04$ ) were seen in the KRAS wild-type population $(\mathrm{n}=90)(126)$.

\section{Towards personalized care}

CRC is the third leading cause of cancer mortality worldwide and prognosis for CRC patients is directly related to the timing of diagnosis. When detected early, it is often cured with surgery alone. For more advanced or metastatic disease, chemotherapy is added to surgical treatment. As described so far, several alterations at molecular level favour CRC onset, progression and metastasis. Molecular characterization of cancer associated mutations gives valuable information on disease prognosis and response to therapy.

Current clinical methods for prognostication in CRC are based on the American Joint Committee on Cancer (AJCC), TNM staging classification. In the real life the relationship between TNM stage and prognosis is much more complex, because each cancer stage is also a heterogeneous group (127).

The advent of NGS technology allowed a better, rapidly and also cheaper molecular characterization of cancers. However, clinically relevant biomarkers can be measured in a variety of ways, from mutations in the coding DNA to dysfunctional proteins found by specific activity assays $(128,129)$.

Despite significant progress in colon cancer research, the translation of genetic discoveries into diagnostic tests for colon cancer patients has been difficult and the function of most of the mutations remain ambiguous. Few are genetic bio-markers that today start to have a clinical value as prognostic and/or therapeutic predictive markers, including MSI status and EGF signaling pathway.

There are now strong evidence that MSI is associated with improved prognosis but decreased response to 5-FU-based chemotherapy (130-133).

Concerning EGF signaling, two monoclonal antibodies against EGFR, cetuximab and panitumumab, are now commercially available (134). They are approved for use in combination with 5-FU, leucovorin and oxaliplatin (FOLFOX) or 5-FU, leucovorin and irinotecan (FOLFIRI) for stage IV metastatic CRC (135-137). Unfortunately, efficacy of these regimens remains modest with $8-25 \%$ objective response rates because of great Ras/Raf mutation rate that are present in CRC (138). It has been suggested that PTEN alterations and PI3KCA mutations also give the same effect. With implementation of NGS towards personalized care, molecular characterization of sporadic colorectal cancers is assuming increased importance. Kras, Braf and MSI are already routinely used in clinical practice, however, in our opinion, PTEN and/or PI3KCA determination needs to be improved as diagnostic, prognostic and predictive molecular biomarker in CRC management. We also suggest that GSK-3 $\beta$ could represent an interesting target for colorectal cancer therapy, in view of its central role in molecular signaling pathway cross-talk and EMT regulation.

\section{Conclusion}

As described in this review, CRCs represent a very heterogeneous group of disorders both in the biological behavior and at molecular level, in which different patterns of mutations contribute to the onset and progression and are responsible for specific aggressiveness and also for response to the therapy. NGS technology are going to improve the molecular characterization of sporadic and hereditary diseases allowing standardization of personalized care. Therefore, it is becoming of great importance to standardize the methodology for new predictive, diagnostic and prognostic biomarkers in colorectal cancer, such as PTEN and/or PI3KCA. We also believe that 
discovery of new therapeutic targets represents the goal of biomedical research on $\mathrm{CRC}$ at the moment, since majority of CRC are insensitive to EGFR inhibitor therapy, because of their positivity for mutations in the genes Kras, Braf, PI3KCA and PTEN. We suggest that epithelial to mesenchymal transition could represent an interesting mechanism for therapeutic target, because it seems a common mechanism on extensive molecular heterogeneity that characterises CRCs. Moreover, as we recently suggested, GSK-3 $\beta$ could represent an interesting target for colorectal cancer therapy (55).

\section{References}

1. Pancione M, Remo A and Colantuoni V: Genetic and epigenetic events generate multiple pathways in colorectal cancer progression. Pathol Res Int 2012: 509348, 2012.

2. Ewing I, Hurley JJ, Josephides E and Millar A: The molecular genetics of colorectal cancer. Frontline Gastroenterol 5: 26-30, 2014.

3. Vogelstein B, Fearon ER, Hamilton SR, Kern SE, Preisinger AC, Leppert M, Nakamura Y, White R, Smits AM and Bos JL: Genetic alterations during colorectal-tumor development. N Engl J Med 319: 525-532, 1988.

4. Burt RW: Colon cancer screening. Gastroenterology 119: $837-853,2000$.

5. Jasperson KW, Tuohy TM, Neklason DW and Burt RW: Hereditary and familial colon cancer. Gastroenterology 138: 2044-2058, 2010.

6. Duraturo F, Liccardo R, Cavallo A, De Rosa M, Grosso M and Izzo P: Association of low-risk MSH3 and MSH2 variant alleles with Lynch syndrome: Probability of synergistic effects. Int J Cancer 129: 1643-1650, 2011.

7. Rustgi AK: The genetics of hereditary colon cancer (Review). Genes Dev 21: 2525-2538, 2007.

8. Peifer M: Developmental biology: colon construction. Nature 420: 274-275, 277, 2002.

9. Kosinski C, Li VS, Chan AS, Zhang J, Ho C, Tsui WY, Chan TL, Mifflin RC, Powell DW, Yuen ST, et al: Gene expression patterns of human colon tops and basal crypts and BMP antagonists as intestinal stem cell niche factors. Proc Natl Acad Sci USA 104: 15418-15423, 2007.

10. Medema JP and Vermeulen L: Microenvironmental regulation of stem cells in intestinal homeostasis and cancer (Review). Nature 474: 318-326, 2011.

11. Goel A, Nagasaka T, Arnold CN, Inoue T, Hamilton C, Niedzwiecki D, Compton C, Mayer RJ, Goldberg R, Bertagnolli MM, et al: The CpG island methylator phenotype and chromosomal instability are inversely correlated in sporadic colorectal cancer. Gastroenterology 132: 127-138, 2007.

12. Sideris M and Papagrigoriadis S: Molecular biomarkers and classification models in the evaluation of the prognosis of colorectal cancer (Review). Anticancer Res 34: 2061-2068, 2014.

13. Pino MS and Chung DC: The chromosomal instability pathway in colon cancer. Gastroenterology 138: 2059-2072, 2010.

14. Boland CR and Goel A: Microsatellite instability in colorectal cancer (Review). Gastroenterology 138: 2073-2087.e3, 2010.

15. Colussi D, Brandi G, Bazzoli F and Ricciardiello L: Molecular pathways involved in colorectal cancer: implications for disease behavior and prevention. Int J Mol Sci 14: 16365-16385, 2013.

16. Markowitz SD and Bertagnolli MM: Molecular origins of cancer: molecular basis of colorectal cancer. N Engl J Med 361: 2449-2460, 2009.

17. Najdi R, Holcombe RF and Waterman ML: Wnt signaling and colon carcinogenesis: beyond APC. J Carcinog 10: 5, 2011.

18. MacDonald BT, Tamai K and He X: Wnt/ $\beta$-catenin signaling: components, mechanisms and diseases. Dev Cell 17: 9-26, 2009 .

19. Polakis P: Wnt signaling and cancer. Genes Dev 14: 1837-51, 2000.

20. Giles RH, van Es JH and Clevers H: Caught up in a Wnt storm: Wnt signaling in cancer. Biochim Biophys Acta 1653: 1-24, 2003.

21. Dejana E: The role of wnt signaling in physiological and pathological angiogenesis. Circ Res 107: 943-952, 2010.

22. Planutis $K$, Planutiene $M$ and Holcombe RF: A novel signaling pathway regulates colon cancer angiogenesis through Norrin. Sci Rep 4: 5630, 2014
23. Shaw RJ and Cantley LC: Ras, $\mathrm{PI}(3) \mathrm{K}$ and mTOR signalling controls tumour cell growth. Nature 441: 424-430, 2006.

24. Fresno Vara JA, Casado E, de Castro J, Cejas P, Belda-Iniesta C and González-Barón M: PI3K/Akt signalling pathway and cancer. Cancer Treat Rev 30: 193-204, 2004.

25. Testa JR and Bellacosa A: AKT plays a central role in tumorigenesis. Proc Natl Acad Sci USA 98: 10983-10985, 2001.

26. Martini M, De Santis MC, Braccini L, Gulluni F and Hirsch E: PI3K/AKT signaling pathway and cancer: an updated review. Ann Med 46: 372-383, 2014.

27. Porta C, Paglino C and Mosca A: Targeting PI3K/Akt/mTOR signaling in cancer. Front Oncol 4: 64, 2014.

28. Lee G, Goretsky T, Managlia E, Dirisina R, Singh AP Brown JB, May R, Yang GY, Ragheb JW, Evers BM, et al: Phosphoinositide 3-kinase signaling mediates $\beta$-catenin activation in intestinal epithelial stem and progenitor cells in colitis. Gastroenterology 139: 869-881, 2010.

29. Simpson L and Parsons R: PTEN: life as a tumor suppressor. Exp Cell Res 264: 29-41, 2001.

30. Salmena L, Carracedo A and Pandolfi PP: Tenets of PTEN tumor suppression. Cell 133: 403-414, 2008.

31. Manfredi M: Hereditary hamartomatous polyposis syndromes: understanding the disease risks as children reach adulthood. Gastroenterol Hepatol (NY) 6: 185-196, 2010.

32. Eng C: PTEN: one gene, many syndromes. Hum Mutat 22: 183-198, 2003.

33. Galatola M, Paparo L, Duraturo F, Turano M, Rossi GB, Izzo P and De Rosa M: B catenin and cytokine pathway dysregulation in patients with manifestations of the 'PTEN hamartoma tumor syndrome'. BMC Med Genet 13: 28, 2012.

34. Alimonti A, Carracedo A, Clohessy JG, Trotman LC, Nardella C, Egia A, Salmena L, Sampieri K, Haveman WJ, Brogi E, et al: Subtle variations in Pten dose determine cancer susceptibility. Nat Genet 42: 454-458, 2010

35. Paparo L, Rossi GB, Delrio P, Rega D, Duraturo F, Liccardo R, Debellis M, Izzo P and De Rosa M: Differential expression of PTEN gene correlates with phenotypic heterogeneity in three cases of patients showing clinical manifestations of PTEN hamartoma tumour syndrome. Hered Cancer Clin Pract 11: 8, 2013.

36. Malumbres $M$ and Barbacid M: RAS oncogenes: the first 30 years. Nat Rev Cancer 3: 459-465, 2003.

37. Scaltriti $\mathrm{M}$ and Baselga J: The epidermal growth factor receptor pathway: a model for targeted therapy. Clin Cancer Res 12: 5268-5272, 2006.

38. Hallberg B, Rayter SI and Downward J: Interaction of Ras and Raf in intact mammalian cells upon extracellular stimulation. J Biol Chem 269: 3913-3916, 1994.

39. Liebmann C: Regulation of MAP kinase activity by peptide receptor signalling pathway: paradigms of multiplicity. Cell Signal 13: 777-785, 2001.

40. Shao DD, Xue W, Krall EB, Bhutkar A, Piccioni F, Wang X, Schinzel AC, Sood S, Rosenbluh J, Kim JW, et al: KRAS and YAP1 converge to regulate EMT and tumor survival. Cell 158: 171-184, 2014.

41. Chen F and Castranova V: Nuclear factor-kappaB, an unappreciated tumor suppressor. Cancer Res 67: 11093-11098, 2007.

42. Perkins ND: NF- $\mathrm{KB}$ : tumor promoter or suppressor? Trends Cell Biol 14: 64-69, 2004.

43. Du Q and Geller DA: Cross-regulation between Wnt and NF- $\kappa B$ signaling pathways. For Immunopathol Dis Therap 1: 155-181, 2010.

44. Hoesel B and Schmid JA: The complexity of NF- $\mathrm{BB}$ signaling in inflammation and cancer. Mol Cancer 12: 1-15, 2013.

45. McCubrey JA, Steelman LS, Bertrand FE, Davis NM, Sokolosky M, Abrams SL, Montalto G, D'Assoro AB, Libra M, Nicoletti F, et al: GSK-3 as potential target for therapeutic intervention in cancer. Oncotarget 5: 2881-2911, 2014.

46. Li H, Huang K, Liu X, Liu J, Lu X, Tao K, Wang G and Wang J: Lithium chloride suppresses colorectal cancer cell survival and proliferation through $\mathrm{ROS} / \mathrm{GSK}-3 \beta / \mathrm{NF}-\kappa \mathrm{B}$ signaling pathway. Oxid Med Cell Longev 2014: 241864, 2014.

47. Mishra R: Glycogen synthase kinase $3 \beta$ : can it be a target for oral cancer. Mol Cancer 9: 144, 2010.

48. Loboda A, Nebozhyn MV, Watters JW, Buser CA, Shaw PM, Huang PS, Van't Veer L, Tollenaar RA, Jackson DB, Agrawal D, et al: EMT is the dominant program in human colon cancer. BMC Med Genomics 4: 9, 2011.

49. De Craene B and Berx G: Regulatory networks defining EMT during cancer initiation and progression. Nat Rev Cancer 13: 97-110, 2013. 
50. Batlle E, Sancho E, Francí C, Domínguez D, Monfar M, Baulida J and García De Herreros A: The transcription factor Snail is a repressor of E-cadherin gene expression in epithelial tumour cells. Nat Cell Biol 2: 84-89, 2000.

51. Cano A, Pérez-Moreno MA, Rodrigo I, Locascio A, Blanco MJ, del Barrio MG, Portillo $F$ and Nieto MA: The transcription factor Snail controls epithelial-mesenchymal transitions by repressing E-cadherin expression. Nat Cell Biol 2: 76-83, 2000.

52. Li X, Pei D and Zheng H; Li X1: Transitions between epithelial and mesenchymal states during cell fate conversions. Protein Cell 5: 580-591, 2014.

53. Mani SA, Guo W, Liao MJ, Eaton EN, Ayyanan A, Zhou AY, Brooks M, Reinhard F, Zhang CC, Shipitsin M, et al: The epithelial-mesenchymal transition generates cells with properties of stem cells. Cell 133: 704-715, 2008 .

54. Giannelli G, Villa $\mathrm{E}$ and Lahn M: Transforming growth factor- $\beta$ as a therapeutic target in hepatocellular carcinoma. Cancer Res 74: 1890-1894, 2014

55. Costabile V, Duraturo F, Delrio P, Rega D, Pace U, Liccardo R, Rossi GB, Genesio R, Nitsch L, Izzo P, et al: Lithium chloride induces mesenchymal to epithelial reverting transition in primary colon cancer cell cultures. Int J Oncol 46: 1913-1923, 2015.

56. Jasperson KW, Tuohy TM, Neklason DW and Burt RW: Hereditary and familial colon cancer. Gastroenterology 138: 2044-2058, 2010.

57. Gallagher DJ, Smith JD, Offit K and Stadler ZK: Diagnosing hereditary colorectal cancer. Clin Colorectal Cancer 9: 205-211, 2010.

58. Lucci-Cordisco E, Risio M, Venesio T and Genuardi M: The growing complexity of the intestinal polyposis syndromes. Am J Med Genet A 161A: 2777-2787, 2013.

59. De Rosa M, Duraturo F, Liccardo R and Izzo P: Hereditary gastrointestinal polyposis: diagnosis, genetic test and risk assessment. Open J Genet 3: 50-58, 2013.

60. Kolfschoten NE, Wouters MW, Gooiker GA, Eddes EH, Kievit J, Tollenaar RA and Marang-van de Mheen PJ: Dutch surgical colorectal audit group: nonelective colon cancer resections in elderly patients: results from the dutch surgical colorectal audit. Dig Surg 29: 412-419, 2012.

61. Smothers L, Hynan L, Fleming J, Turnage R, Simmang C and Anthony T: Emergency surgery for colon carcinoma. Dis Colon Rectum 46: 24-30, 2003

62. Kekelidze M, D’Errico L, Pansini M, Tyndall A and Hohmann J: Colorectal cancer: current imaging methods and future perspectives for the diagnosis, staging and therapeutic response evaluation. World J Gastroenterol 19: 8502-8514, 2013.

63. Leufkens AM, van den Bosch MA, van Leeuwen MS and Siersema PD: Diagnostic accuracy of computed tomography for colon cancer staging: a systematic review. Scand J Gastroenterol 46: 887-894, 2011 .

64. Mitry E, Guiu B, Cosconea S, Jooste V, Faivre J and Bouvier AM: Epidemiology, management and prognosis of colorectal cancer with lung metastases: a 30-year population-based study. Gut 59 . $1383-1388,2010$

65. Barret M, Boustiere C, Canard JM, Arpurt JP, Bernardini D, Bulois P, Chaussade S, Heresbach D, Joly I, Lapuelle J, et al: Société Française d'Endoscopie Digestive: factors associated with adenoma detection rate and diagnosis of polyps and colorectal cancer during colonoscopy in France: results of a prospective, nationwide survey. PLoS One 8: e68947, 2013.

66. Kaminski MF, Regula J, Kraszewska E, Polkowski M, Wojciechowska U, Didkowska J, Zwierko M, Rupinski M, Nowacki MP and Butruk E: Quality indicators for colonoscopy and the risk of interval cancer. N Engl J Med 362: 1795-1803, 2010.

67. Zauber AG, Winawer SJ, O'Brien MJ, Lansdorp-Vogelaar I, van Ballegooijen M, Hankey BF, Shi W, Bond JH, Schapiro M, Panish JF, et al: Colonoscopic polypectomy and long-term prevention of colorectal-cancer deaths. N Engl J Med 366 687-696, 2012

68. Graser A, Stieber P, Nagel D, Schäfer C, Horst D, Becker CR, Nikolaou K, Lottes A, Geisbüsch S, Kramer H, et al: Comparison of CT colonography, colonoscopy, sigmoidoscopy and faecal occult blood tests for the detection of advanced adenoma in an average risk population. Gut 58: 241-248, 2009.

69. Pickhardt PJ, Hassan C, Halligan S and Marmo R: Colorectal cancer: CT colonography and colonoscopy for detection - systematic review and meta-analysis. Radiology 259: 393-405, 2011
70. Pullens HJ, van Leeuwen MS, Laheij RJ, Vleggaar FP and Siersema PD: CT-colonography after incomplete colonoscopy: What is the diagnostic yield? Dis Colon Rectum 56: 593-599, 2013.

71. Atkin W, Dadswell E, Wooldrage K, Kralj-Hans I, von Wagner C, Edwards R, Yao G, Kay C, Burling D, Faiz O, et al: SIGGAR investigators: computed tomographic colonography versus colonoscopy for investigation of patients with symptoms suggestive of colorectal cancer (SIGGAR): a multicentre randomised trial. Lancet 381: 1194-1202, 2013.

72. Edge SB and Compton CC: The American Joint Committee on cancer: the 7th edition of the AJCC cancer staging manual and the future of TNM. Ann Surg Oncol 17: 1471-1474, 2010.

73. Bipat S, Niekel MC, Comans EF, Nio CY, Bemelman WA, Verhoef $C$ and Stoker J: Imaging modalities for the staging of patients with colorectal cancer. Neth J Med 70: 26-34, 2012.

74. Floriani I, Torri V, Rulli E, Garavaglia D, Compagnoni A, Salvolini L and Giovagnoni A: Performance of imaging modalities in diagnosis of liver metastases from colorectal cancer: a systematic review and meta-analysis. J Magn Reson Imaging 31: 19-31, 2010.

75. Niekel MC, Bipat S and Stoker J: Diagnostic imaging of colorectal liver metastases with CT, MR imaging, FDG PET, and/or FDG PET/CT: a meta-analysis of prospective studies including patients who have not previously undergone treatment. Radiology 257: 674-684, 2010.

76. Dighe S, Blake H, Koh MD, Swift I, Arnaout A, Temple L, Barbachano Y and Brown G: Accuracy of multidetector computed tomography in identifying poor prognostic factors in colonic cancer. Br J Surg 97: 1407-1415, 2010.

77. Dighe S, Purkayastha S, Swift I, Tekkis PP, Darzi A, A'Hern R and Brown G: Diagnostic precision of CT in local staging of colon cancers: A meta-analysis. Clin Radiol 65: 708-719, 2010.

78. Schmoll HJ, Van Cutsem E, Stein A, Valentini V, Glimelius B, Haustermans K, Nordlinger B, van de Velde CJ, Balmana J, Regula J, et al: ESMO consensus guidelines for management of patients with colon and rectal cancer. a personalized approach to clinical decision making. Ann Oncol 23: 2479-2516, 2012

79. Glimelius B, Beets-Tan R, Blomqvist L, Brown G, Nagtegaal I, Påhlman L, Quirke P, Valentini V and van de Velde C: Mesorectal fascia instead of circumferential resection margin in preoperative staging of rectal cancer. J Clin Oncol 29: 2142-2143, 2011.

80. van de Velde CJ, Aristei C, Boelens PG, Beets-Tan RG, Blomqvist L, Borras JM, van den Broek CB, Brown G, Coebergh JW, Cutsem EV, et al: European registration of cancer care: EURECCA colorectal: multidisciplinary mission statement on better care for patients with colon and rectal cancer in Europe. Eur J Cancer 49: 2784-2790, 2013.

81. Torkzad MR, Påhlman L and Glimelius B: Magnetic resonance imaging (MRI) in rectal cancer: a comprehensive review. Insights Imaging 1: 245-267, 2010.

82. Poston GJ, Tait D, O'Connell S, Bennett A and Berendse S Guideline development group: diagnosis and management of colorectal cancer: summary of NICE guidance. BMJ 343: d6751, 2011.

83. Swartling T, Kälebo P, Derwinger K, Gustavsson B and Kurlberg G: Stage and size using magnetic resonance imaging and endosonography in neoadjuvantly-treated rectal cancer. World J Gastroenterol 19: 3263-3271, 2013

84. Hohenberger W, Weber K, Matzel K, Papadopoulos T and Merkel S: Standardized surgery for colonic cancer: complete mesocolic excision and central ligation - technical notes and outcome. Colorectal Dis 11: 354-364, discussion 364-365, 2009.

85. Sehgal R and Coffey JC: Historical development of mesenteric anatomy provides a universally applicable anatomic paradigm for complete/total mesocolic excision. Gastroenterol Rep (Oxf) 2: 245-250, 2014

86. Søndenaa K, Quirke P, Hohenberger W, Sugihara K, Kobayashi H, Kessler H, Brown G, Tudyka V, D'Hoore A, Kennedy RH, et al: The rationale behind complete mesocolic excision (CME) and a central vascular ligation for colon cancer in open and laparoscopic surgery: proceedings of a consensus conference. Int $\mathrm{J}$ Colorectal Dis 29: 419-428, 2014.

87. Siani LM and Pulica C: Stage I-IIIC right colonic cancer treated with complete mesocolic excision and central vascular ligation: quality of surgical specimen and long term oncologic outcome according to the plane of surgery. Minerva Chir 69: 199-208, 2014. 
88. Sagar J: Colorectal stents for the management of malignant colonic obstructions. Cochrane Database Syst Rev 11: CD007378, 2011. Review.

89. Fuccio L, Cennamo V and de Bellis M: Risk factors for stent-related adverse events in patients with obstructive colorectal cancer: are we missing something? Gastrointest Endosc 80: 742-743, 2014.

90. Fuccio L, Correale L, Arezzo A, Repici A, Manes G, Trovato C, Mangiavillano B, Manno M, Cortelezzi CC, Dinelli M, et al; KRASTENT Study Group: influence of K-ras status and anti-tumour treatments on complications due to colorectal self-expandable metallic stents: a retrospective multicentre study. Dig Liver Dis 46: 561-567, 2014.

91. Yang TX and Chua TC: Single-incision laparoscopic colectomy versus conventional multiport laparoscopic colectomy: a meta-analysis of comparative studies. Int J Colorectal Dis 28: 89-101, 2013.

92. Mynster T, Hammer J and Wille-Jørgensen P: Preliminary results after single-port laparoscopic colonic surgery. Dan Med J 59: A4551, 2012.

93. Huscher CG, Mingoli A, Sgarzini G, Mereu A, Binda B, Brachini G and Trombetta S: Standard laparoscopic versus single-incision laparoscopic colectomy for cancer: early results of a randomized prospective study. Am J Surg 204: 115-120, 2012.

94. Wolthuis AM, Penninckx F, Fieuws S and D'Hoore A: Outcomes for case-matched single-port colectomy are comparable with conventional laparoscopic colectomy. Colorectal Dis 14: 634-641, 2012.

95.Ramos-Valadez DI, Ragupathi M, Nieto J, Patel CB, Miller S, Pickron TB and Haas EM: Single-incision versus conventional laparoscopic sigmoid colectomy: a case-matched series. Surg Endosc 26: 96-102, 2012.

96. Tyler JA, Fox JP, Desai MM, Perry WB and Glasgow SC: Outcomes and costs associated with robotic colectomy in the minimally invasive era. Dis Colon Rectum 56: 458-466, 2013

97. Baek SK, Carmichael JC and Pigazzi A: Robotic surgery: colon and rectum. Cancer J 19: 140-146, 2013.

98. Glimelius B, Beets-Tan R, Blomqvist L, Brown G, Nagtegaal I, Påhlman L, Quirke P, Valentini V and van de Velde C: Mesorectal fascia instead of circumferential resection margin in preoperative staging of rectal cancer. J Clin Oncol 29: 2142-2143, 2011.

99. Sgourakis G, Lanitis S, Gockel I, Kontovounisios C, Karaliotas C, Tsiftsi K, Tsiamis A and Karaliotas CC: Transanal endoscopic microsurgery for $\mathrm{T} 1$ and $\mathrm{T} 2$ rectal cancers: a meta-analysis and meta-regression analysis of outcomes. Am Surg 77: 761-772, 2011.

100. Guerrieri M, Gesuita R, Ghiselli R, Lezoche G, Budassi A and Baldarelli M: Treatment of rectal cancer by transanal endoscopic microsurgery: experience with 425 patients. World J Gastroenterol 20: 9556-9563, 2014

101. Matz J and Matz A: Use of a SILS port in transanal endoscopic microsurgery in the setting of a community hospital. J Laparoendosc Adv Surg Tech A 22: 93-96, 2012.

102. Atallah S, Albert M and Larach S: Transanal minimally invasive surgery: a giant leap forward. Surg Endosc 24: 2200-2205, 2010

103. Guillou PJ, Quirke P, Thorpe H, Walker J, Jayne DG Smith AM, Heath RM and Brown JM: MRC CLASICC trial group: short-term endpoints of conventional versus laparoscopic-assisted surgery in patients with colorectal cancer (MRC CLASICC trial): multicentre, randomised controlled trial. Lancet 365: 1718-1726, 2005.

104. Jayne DG, Thorpe HC, Copeland J, Quirke P, Brown JM and Guillou PJ: Five-year follow-up of the Medical Research Council CLASICC trial of laparoscopically assisted versus open surgery for colorectal cancer. Br J Surg 97: 1638-1645, 2010.

105. Kang SB, Park JW, Jeong SY, Nam BH, Choi HS, Kim DW, Lim SB, Lee TG, Kim DY, Kim JS, et al: Open versus laparoscopic surgery for mid or low rectal cancer after neoadjuvant chemoradiotherapy (COREAN trial): short-term outcomes of an open-label randomised controlled trial. Lancet Oncol 11: 637-645, 2010.

106. van der Pas MH, Haglind E, Cuesta MA, Fürst A, Lacy AM, Hop WC and Bonjer HJ: Colorectal cancer laparoscopic or open resection II (COLOR II) study group: laparoscopic versus open surgery for rectal cancer (COLOR II): short-term outcomes of a randomised, phase 3 trial. Lancet Oncol 14: 210-218, 2013.
107. Yang Y, Wang F, Zhang P, Shi C, Zou Y, Qin H and Ma Y: Robot-assisted versus conventional laparoscopic surgery for colorectal disease, focusing on rectal cancer: a meta-analysis. Ann Surg Oncol 19: 3727-3736, 2012

108. Lin S, Jiang HG, Chen ZH, Zhou SY, Liu XS and Yu JR: Meta-analysis of robotic and laparoscopic surgery for treatment of rectal cancer. World J Gastroenterol 17: 5214-5220, 2011.

109.Park JS, Choi GS, Lim KH, Jang YS and Jun SH: S052: a comparison of robot-assisted, laparoscopic, and open surgery in the treatment of rectal cancer. Surg Endosc 25: 240-248, 2011.

110. Kim JC, Yang SS, Jang TY, Kwak JY, Yun MJ and Lim SB: Open versus robot-assisted sphincter-saving operations in rectal cancer patients: techniques and comparison of outcomes between groups of 100 matched patients. Int J Med Robot 8: 468-475, 2012.

111. Kim JY, Kim N-K, Lee KY, Hur H, Min BS and Kim JH: A comparative study of voiding and sexual function after total mesorectal excision with autonomic nerve preservation for rectal cancer: laparoscopic versus robotic surgery. Ann Surg Oncol 19: 2485-2493, 2012.

112. D'Annibale A, Pernazza G, Monsellato I, Pende V, Lucandri G, Mazzocchi P and Alfano G: Total mesorectal excision: a comparison of oncological and functional outcomes between robotic and laparoscopic surgery for rectal cancer. Surg Endosc 27: 1887-1895, 2013

113. Luca F, Valvo M, Ghezzi TL, Zuccaro M, Cenciarelli S, Trovato C, Sonzogni A and Biffi R: Impact of robotic surgery on sexual and urinary functions after fully robotic nerve-sparing total mesorectal excision for rectal cancer. Ann Surg 257: 672-678, 2013

114. Collinson FJ, Jayne DG, Pigazzi A, Tsang C, Barrie JM, Edlin R, Garbett C, Guillou P, Holloway I, Howard H, et al: An international, multicentre, prospective, randomised, controlled, unblinded, parallel-group trial of robotic-assisted versus standard laparoscopic surgery for the curative treatment of rectal cancer. Int J Colorectal Dis 27: 233-241, 2012.

115. Memon S, Heriot AG, Murphy DG, Bressel M and Lynch AC: Robotic versus laparoscopic proctectomy for rectal cancer: a meta-analysis. Ann Surg Oncol 19: 2095-2101, 2012.

116. Trastulli S, Farinella E, Cirocchi R, Cavaliere D, Avenia N, Sciannameo F, Gullà N, Noya G and Boselli C: Robotic resection compared with laparoscopic rectal resection for cancer: systematic review and meta-analysis of short-term outcome. Colorectal Dis 14: e134-e156, 2012.

117. Valentini V, Aristei C, Glimelius B, Minsky BD, Beets-Tan R, Borras JM, Haustermans K, Maingon P, Overgaard J, Pahlman L, et al: Scientific committee: multidisciplinary rectal cancer management: 2nd European rectal cancer consensus conference (EURECA-CC2). Radiother Oncol 92: 148-163, 2009.

118. Sauer R, Liersch T, Merkel S, Fietkau R, Hohenberger W, Hess C, Becker H, Raab HR, Villanueva MT, Witzigmann H, et al: Preoperative versus postoperative chemoradiotherapy for locally advanced rectal cancer: results of the German CAO/ARO/AIO-94 randomized phase III trial after a median follow-up of 11 years. J Clin Oncol 30: 1926-1933, 2012.

119. Schmoll HJ, Van Cutsem E, Stein A, Valentini V, Glimelius B, Haustermans K, Nordlinger B, van de Velde CJ, Balmana J, Regula J, et al: ESMO Consensus Guidelines for management of patients with colon and rectal cancer. A personalized approach to clinical decision making. Ann Oncol 23: 2479-2516, 2012.

120. Pettersson D, Glimelius B, Iversen H, Johansson H, Holm T and Martling A: Impaired postoperative leucocyte counts after preoperative radiotherapy for rectal cancer in the Stockholm III Trial. Br J Surg 100: 969-975, 2013.

121. Pettersson D, Cedermark B, Holm T, Radu C, Påhlman L, Glimelius B and Martling A: Interim analysis of the Stockholm III trial of preoperative radiotherapy regimens for rectal cancer. Br J Surg 97: 580-587, 2010.

122. Bujko K, Nowacki MP, Nasierowska-Guttmejer A, Michalski W, Bebenek M and Kryj M: Long-term results of a randomized trial comparing preoperative short-course radiotherapy with preoperative conventionally fractionated chemoradiation for rectal cancer. Br J Surg 93: 1215-1223, 2006.

123. Ngan SY, Burmeister B, Fisher RJ, Solomon M, Goldstein D, Joseph D, Ackland SP, Schache D, McClure B, McLachlan SA, et al: Randomized trial of short-course radiotherapy versus long-course chemoradiation comparing rates of local recurrence in patients with T3 rectal cancer: trans-tasman radiation oncology group trial 01.04. J Clin Oncol 30: 3827-3833, 2012. 
124. Siegel R, Burock S, Wernecke KD, Kretzschmar A, Dietel M, Loy V, Koswig S, Budach V and Schlag PM: Preoperative short-course radiotherapy versus combined radiochemotherapy in locally advanced rectal cancer: a multi-centre prospectively randomised study of the Berlin Cancer Society. BMC Cancer 9: $50,2009$.

125.Hofheinz RD, Wenz F, Post S, Matzdorff A, Laechelt S, Hartmann JT, Müller L, Link H, Moehler M, Kettner E, et al: Chemoradiotherapy with capecitabine versus fluorouracil for locally advanced rectal cancer: a randomised, multicentre, non-inferiority, phase 3 trial. Lancet Oncol 13: 579-588, 2012.

126. Avallone A, Delrio P, Pecori B, Tatangelo F, Petrillo A, Scott N, Marone P, Aloi L, Sandomenico C, Lastoria S, et al: Oxaliplatin plus dual inhibition of thymidilate synthase during preoperative pelvic radiotherapy for locally advanced rectal carcinoma: long-term outcome. Int J Radiat Oncol Biol Phys 79: 670-676, 2011.

127. Gunderson LL, Jessup JM, Sargent DJ, Greene FL and Stewart AK: Revised TN categorization for colon cancer based on national survival outcomes data. J Clin Oncol 28: 264-271, 2010.

128. Bombard Y, Bach PB and Offit K: Translating genomics in cancer care. J Natl Compr Canc Netw 11: 1343-1353, 2013.

129. Ross JS and Cronin M: Whole cancer genome sequencing by next-generation methods. Am J Clin Pathol 136: 527-539, 2011.

130. Ribic CM, Sargent DJ, Moore MJ, Thibodeau SN, French AJ, Goldberg RM, Hamilton SR, Laurent-Puig P, Gryfe R, Shepherd LE, et al: Tumor microsatellite-instability status as a predictor of benefit from fluorouracil-based adjuvant chemotherapy for colon cancer. N Engl J Med 349: 247-257, 2003.

131. Bertagnolli MM, Niedzwiecki D, Compton CC, Hahn HP, Hall M, Damas B, Jewell SD, Mayer RJ, Goldberg RM, Saltz LB, et al: Microsatellite instability predicts improved response to adjuvant therapy with irinotecan, fluorouracil, and leucovorin in stage III colon cancer: cancer and leukemia group B protocol 89803. J Clin Oncol 27: 1814-1821, 2009.
132. Des Guetz G, Schischmanoff O, Nicolas P, Perret GY, Morere JF and B: Does microsatellite instability predict the efficacy of adjuvant chemotherapy in colorectal cancer? A systematic review with meta-analysis. Eur J Cancer 45: 1890-1896, 2009.

133. Sargent DJ, Marsoni S, Monges G, Thibodeau SN, Labianca R, Hamilton SR, French AJ, Kabat B, Foster NR, Torri V, et al: Defective mismatch repair as a predictive marker for lack of efficacy of fluorouracil-based adjuvant therapy in colon cancer. J Clin Oncol 28: 3219-3226, 2010.

134. Downward J: Targeting RAS signalling pathways in cancer therapy. Nat Rev Cancer 3: 11-22, 2003.

135. Tveit KM, Guren T, Glimelius B, Pfeiffer P, Sorbye H, Pyrhonen S, Sigurdsson F, Kure E, Ikdahl T, Skovlund E, et al: Phase III trial of cetuximab with continuous or intermittent fluorouracil, leucovorin, and oxaliplatin (Nordic FLOX) versus FLOX alone in first-line treatment of metastatic colorectal cancer: the NORDIC-VII study. J Clin Oncol 30: 1755-1762, 2012.

136.Peeters M, Price TJ, Cervantes A, Sobrero AF, Ducreux M, Hotko Y, André T, Chan E, Lordick F, Punt CJ, et al: Randomized phase III study of panitumumab with fluorouracil, leucovorin, and irinotecan (FOLFIRI) compared with FOLFIRI alone as second-line treatment in patients with metastatic colorectal cancer. J Clin Oncol 28: 4706-4713, 2010.

137. Van Cutsem E, Köhne CH, Hitre E, Zaluski J, Chang Chien CR, Makhson A, D'Haens G, Pintér T, Lim R, Bodoky G, et al: Cetuximab and chemotherapy as initial treatment for metastatic colorectal cancer. N Engl J Med 360: 1408-1417, 2009.

138. Bazan V, Migliavacca M, Zanna I, Tubiolo C, Grassi N, Latteri MA, La Farina M, Albanese I, Dardanoni G, Salerno S, et al: Specific codon 13 K-ras mutations are predictive of clinical outcome in colorectal cancer patients, whereas codon 12 K-ras mutations are associated with mucinous histotype. Ann Oncol 13: 1438-1446, 2002. 